\title{
An information processing system for the psychiatric emergency room
}

\author{
LYNN L. PETERSON, KENT O. DANA, JOAN S. REISCH, THOMAS HIBBERD, \\ MAURICE KORMAN, PAUL I. MUNVES, ALVIN J. NORTH, \\ THOMAS A. VAN HOOSE, and FRANK TRIMBOLI \\ University of Texas Health Science Center, Dallas, Texas 75235
}

\begin{abstract}
An information processing system for a psychiatric emergency room is described. Several studies are presented that show the utility of the system. In the first study, variables involved in diagnosis are explicated. The second study attempts to determine the characteristics that distinguish recidivists from nonrecidivists at an emergency room. The third study attempts to find patient variables related to success in short-term treatment programs. The final study is aimed at discovering whether there are psychopathological effects related to the use of inhalants. Together, these studies show the potential of a mental health information system for learning more about the nature of mental disorders and their treatment.
\end{abstract}

This paper describes an information processing system developed for use in a psychiatric emergency room. The nature of the system and a series of studies conducted in the emergency room setting are described.

The setting for these studies was the Parkland Memorial Hospital, a large, urban county hospital in Dallas, Texas; it is the primary teaching hospital of the University of Texas Health Science Center at Dallas. The hospital serves a diverse socioeconomic, racial, and ethnic community of 1.5 million people in Dallas County and the surrounding area. The demographic characteristics of Parkland patients are reasonably representative of the geographical area served, except that the hospital population may be weighted in the direction of the lower socioeconomic groups. The Psychiatric Emergency Room (PER) of Parkland Memorial Hospital provides psychiatric emergency service in this setting. It is the only psychiatric service in this region staffed $24 \mathrm{~h} /$ day, and about $90 \%$ of all psychiatric emergencies occurring in the area are seen at this facility. The hospital also contains an 18-bed inpatient psychiatric ward designed to provide acute care to adults and older adolescents.

Outpatients referred to the PER are evaluated using the specially developed Psychiatric Interview Record (PIR), which provides an orderly and systematic outline for case handling, as well as a comprehensive assessment of variables defining the psychiatric casualty (Peterson, Mays, Wiedeman, Mishelevich, Trimboli, \& Cody, Note 1). This record was developed to facilitate collection of extensive demographic, historical, and clinical data on all patients seen in the PER. The initial section of the PIR dealing with identification and demographic data is completed by the emergency room clerk as soon

Portions of this research were supported by Biomedical Research Institutional Grant 5-S07-RR05426-16 (UTHSCD) to Frank Trimboli. as possible after a patient enters the emergency suite and before he or she is interviewed by the doctor. Information, such as age, sex, and education, is obtained from the patient or the person who accompanied the patient to the emergency room. The remainder of the form is completed by the psychiatrist or psychologist performing the interview. This section includes symptoms, history, diagnosis, and disposition, as well as a survey of past difficulties, including sections on drug and alcohol abuse and danger to self and others. The form is returned to a clerk who checks it for completeness and readies it for input to the computer system, usually within a day or so.

Clinical variables on the PIR are grouped under the general headings of psychiatric history, diagnosis, disposition, and history and mental status. The history and mental status section lists 15 different categories ranging from appearance, mood and affect, and cognitive difficulties through intra/interpersonal difficulties and estimated IQ to drug and alcohol abuse and danger to self and others. Each category contains from 3 to 14 items, each of which is judged by the examiner either on a severity scale of $0=$ none, $1=$ mild, $2=$ moderate, $3=$ severe or on a present/absent basis.

While the staff had received some instruction in the use of the PIR, staff members were not aware of the specific research projects being conducted. Also, insofar as similar data were being collected on all patients for a number of purposes, both clinical and research, it is felt that no staff bias, due to cognizance of or interest in any of the these studies and the selected independent variables, was introduced.

A system of direct information processing was developed for the PER (Peterson, Mays, Dana, Wiedeman, Semler, Trimboli, \& Korman, Note 2). The computer system, called DIPPER (direct information processing system for the PER), has three basic functions: (1) storing patient records, consisting of basic medical history 
and data pertinent to patient visits, (2) retrieving via terminal the data for repeat patients to assist the PER personnel in handling present problems, and (3) providing data for more leisurely perusal for research purposes.

The data are entered into the system running on the DECsystem-10 computer via a CRT terminal located in the PER. Once entered, data are available immediately for case review or for the addition, deletion, or change of items already recorded about the patient. Data are analyzed monthly using the Statistical Analysis System (SAS) (Barr, Goodnight, Sall, \& Helwig, Note 3) on the IBM $370 / 155$ computer; the DECsystem- 10 computer is used to provide remote job entry for the IBM $370 / 155$. The stored data are also routinely stored on magnetic tape for backup purposes and also to create a cumulative master data file on both the DECsystem-10 and the IBM 370/155 computers.

The PIR data base consists of separate files for basic information and visit data. The basic information, including the patient's name, address, and demographic characteristics, is stored and retrieved using a unique sequence number assigned by the computer program at initial entry. Retrieval by name is achieved through the first letter plus a numeric coding of the next three consonant sounds ("soundex") as an index to the sequence number. Each record of a patient's visit to the PER is also linked to the basic information through the sequence number. All the items in the visit records are stored as coded values, although they are expressed in words or short phrases again upon retrieval by the user. They include information about the patient's psychiatric history and diagnosis, disposition, drug and alcohol abuse, and danger to self and others. The interviewer is referred to the original PIR for any detailed notes.

Complete PIR data were obtained and stored for some 11,000 patient visits during a 24 -month period from November 1974 to October 1976. Creation of this extensive data file on psychiatric emergency patients provided a unique opportunity for study of the numerous dimensions of delivery of psychiatric emergency services. The remainder of this report deals with a number of research projects that are either in progress or completed and that explore various dimensions of psychiatric emergency patients and services.

\section{CORRELATES AND CUMULATIVE EFFECTS OF PSYCHIATRIC EMERGENCY DIAGNOSIS}

The first major research effort that emerged explored the correlates and cumulative effects of psychiatric emergency diagnosis (Van Hoose, 1976). Previous research has described the diagnosis (and disposition) of psychiatric emergencies as a complex, multidimensional decision making process that is influenced by demographic, clinical interview, and clirical judgment variables (Lazare, 1976; Muller, Chafetz, \& Blane, 1967; Tischler, 1966). However, the effects of demo- graphic, clinical interview, and clinical judgment variables are usually described as separately affecting diagnosis. Also, despite the complexity of the psychiatric emergency evaluation process, early studies were limited in several respects. Many studies that emphasized only demographic variable effects on diagnosis tended to ignore the impact of patients' clinical attributes on their diagnosis (Muller et al., 1967). Early studies usually reported small samples and simple analyses, thus limiting conclusions and generalizations. Finally, most earlier studies did not utilize a standardized data collection instrument, making inferences from the data subject to increased clinician variance and diagnostic unreliability.

The purpose of this study was to examine the separate and cumulative effects of demographic, clinical interview, and clinical judgment variables on psychiatric emergency diagnosis. The present study also utilized a standardized data collection instrument, a large sample with more sophisticated data analyses, and symptom clusters to differentiate among patient diagnostic groups as recommended by previous research (Huffine \& Craig, 1974; Newmark, Falk, Boren, \& Finch, 1976; Potkay, 1973; Spitzer \& Fleiss, 1974; Yusin, Nihara, \& Mortashed, 1974).

Finally, the present study used the concept of severity of diagnosis, assumed to be an ordinal variable ranging from least to most severe, to clarify relationships between various demographic, clinical interview, and clinical judgment variables and assigned diagnoses. Previous research has suggested that mental disorder (reflected in the diagnostic label) is possibly an ordinal variable (Segal, 1975) and that clinician biases influence the assignment of the patient's diagnosis (Baxter, Chodorkoff, \& Underhill, 1968; Dressler, Prusoff, Mark, \& Shapiro, 1975; Tischler, 1966).

Subjects for this study were 4,891 males and females who visited the PER for the first time during the period of November 1, 1974, through October 31, 1975. Only the initial PER visit on each patient was utilized.

The psychiatric residents and clinical psychology interns who interviewed the subjects rank ordered the 13 available diagnostic categories of the research instrument from least severe to most severe. The rankings for each diagnostic category were then averaged across raters, and these averaged rankings served as the index of level of severity of diagnosis. Interrater agreement was highly significant, and the pooled ratings appeared highly reliable (Van Hoose, 1976).

Cross-tabulations (Nie, Hull, Jenkins, Steinbrenner, \& Bent, 1975) of selected demographic, clinical interview, and clinical judgment variables, with each separate diagnostic category vs. all others pooled, were computed. Variables investigated in the present study are listed in Tables 1-3. Chi square was calculated to determine the presence and magnitude of relationships between these independent variables considered separately and each diagnostic category relative to the total PER sample. The .001 level was chosen as the minimally acceptable 
Table 1

Chi-Square Values for Demographic Variables by Severity of Dingnosis

\begin{tabular}{|c|c|c|c|c|c|c|c|c|c|c|c|}
\hline \multirow{2}{*}{$\begin{array}{c}\text { Demographic } \\
\text { Variables }\end{array}$} & \multicolumn{5}{|c|}{ Less Severe Diagnoses } & \multicolumn{6}{|c|}{ More Severe Diagnoses } \\
\hline & 1 & 2 & 3 & 4 & 5 & 6 & 9 & 10 & 11 & 12 & 13 \\
\hline & \multicolumn{11}{|c|}{ Age } \\
\hline \multirow{3}{*}{$\begin{array}{l}\text { Younger } \\
\text { Older }\end{array}$} & 90.0 & 189.1 & & & 26.1 & & & & & & \\
\hline & & & & & & 254.0 & 46.1 & & & 34.7 & 98.4 \\
\hline & & & & & & Race & & & & & \\
\hline \multirow{3}{*}{$\begin{array}{l}\text { Black } \\
\text { White } \\
\text { Latin }\end{array}$} & & & & & & & & & & & \\
\hline & 14.3 & & & & & 17.5 & & & 54.7 & & \\
\hline & & & & & & Sex & & & & & \\
\hline \multirow{3}{*}{$\begin{array}{l}\text { Female } \\
\text { Male }\end{array}$} & 83.4 & & 154.8 & & & & & & & & \\
\hline & & & & & & 177.7 & & 13.6 & 55.5 & 18.4 & \\
\hline & & & & & & Education & & & & & \\
\hline \multirow{3}{*}{$\begin{array}{l}\text { High School } \\
\text { High School+ }\end{array}$} & & 167.4 & & & & & & & & & \\
\hline & & & & & & & & & 12.4 & & \\
\hline & & & & & & Marital Status & & & & & \\
\hline Married & & & & & & & 13.1 & & & & \\
\hline \multirow{2}{*}{ All Others } & & 86.7 & 36.3 & & & & & 10.5 & 19.4 & & \\
\hline & & & & & & Employed & & & & & \\
\hline Yes & 25.9 & & 44.4 & & & & & & & & \\
\hline \multirow[t]{2}{*}{ No } & & 46.1 & & & & & & & 23.9 & & 23.9 \\
\hline & & & & & & Referral Source & & & & & \\
\hline $\begin{array}{l}\text { Self } \\
\text { Other Parkland Service } \\
\text { Involuntary }\end{array}$ & 221.4 & & 159.3 & & & 43.7 & 51.8 & & 347.2 & 20.1 & 27.6 \\
\hline
\end{tabular}

Note-All reported chi-square values are significant beyond the .001 level; all blanks indicate nonsignificant chi-square values. Diagnoses: (less severe) (1) transient situational disturbance $(N=704)$, (2) behavior disorder of childhood or adolescence ( $N=203)$, (3) neurosis $(N=951)$, (4) sexual deviation $(N=3)$, (5) personality disorder $(N=451)$, (6) psychophysiological disorder $(N=38)$, (more severe) (8) alcoholism ( $N=342)$, (9) affective psychosis $(N=278)$, (10) mental retardation $(N=58)$, (11) nonaffective psychosis $(N=913)$, (12) nonpsychotic organic brain syndrome $(N=125)$, (13) psychotic organic brain syndrome $(N=208)$.

level of significance due to the large number of variables involved.

The cross-tabulations procedure permitted the identification of those variables that are potentially useful in a discriminant analysis to evaluate cumulative variable effects on diagnosis. Four diagnostic categories were eliminated due to extremely small sample size. The remaining nine diagnostic categories were combined into one of four more traditional groups: the neuroses (transient situational disturbance and neurosis), the personality disorders (personality disorder, drug dependence, and alcoholism), the functional psychoses (affective psychosis and nonaffective psychosis), and the organic disorders [nonpsychotic organic brain syndrome (OBS) and psychotic OBS]. These four diagnostic groups maintained the severity continuum established earlier by clinicans, with neuroses considered the least severe and organic disorders the most severe diagnoses.

After examining the cross-tabulations of selected independent variables with diagnosis, 48 variables emerged as potentially useful for inclusion in discriminant analysis functions over chance assignment. The
Statistical Package for the Social Sciences (SPSS) (Nie et al., 1975) was utilized to perform the discriminant analysis, with a twofold purpose: to test the cumulative effects of demographic, clinical interview, and clinical judgment variables in determining diagnosis, and to separate the neuroses, personality disorders, functional psychoses, and organic disorders groups as distinctly as possible.

The discriminant analysis consisted of two phases: analysis of the discriminating ability of the 48 independent variables, and prediction of assignment to the diagnostic groups utilizing the functions derived during analysis. The 4,054 patients that composed the four diagnostic groups represented $83 \%$ of the whole sample. The a priori probability of classification in each group was based on each group's size (see Table 4). Independent variables were entered into the discriminant analysis in a stepwise fashion designed to select an optimal set of variables that would best discriminate among the four diagnostic groups. Significant relationships between demographic, clinical interview, and clinical judgment variables and severity of diagnosis are displayed in Tables 1-3. Results of the discriminant analysis showed 
Table 2

Chi-Square Values for Clinical Interview Variables by Severity of Diagnosis

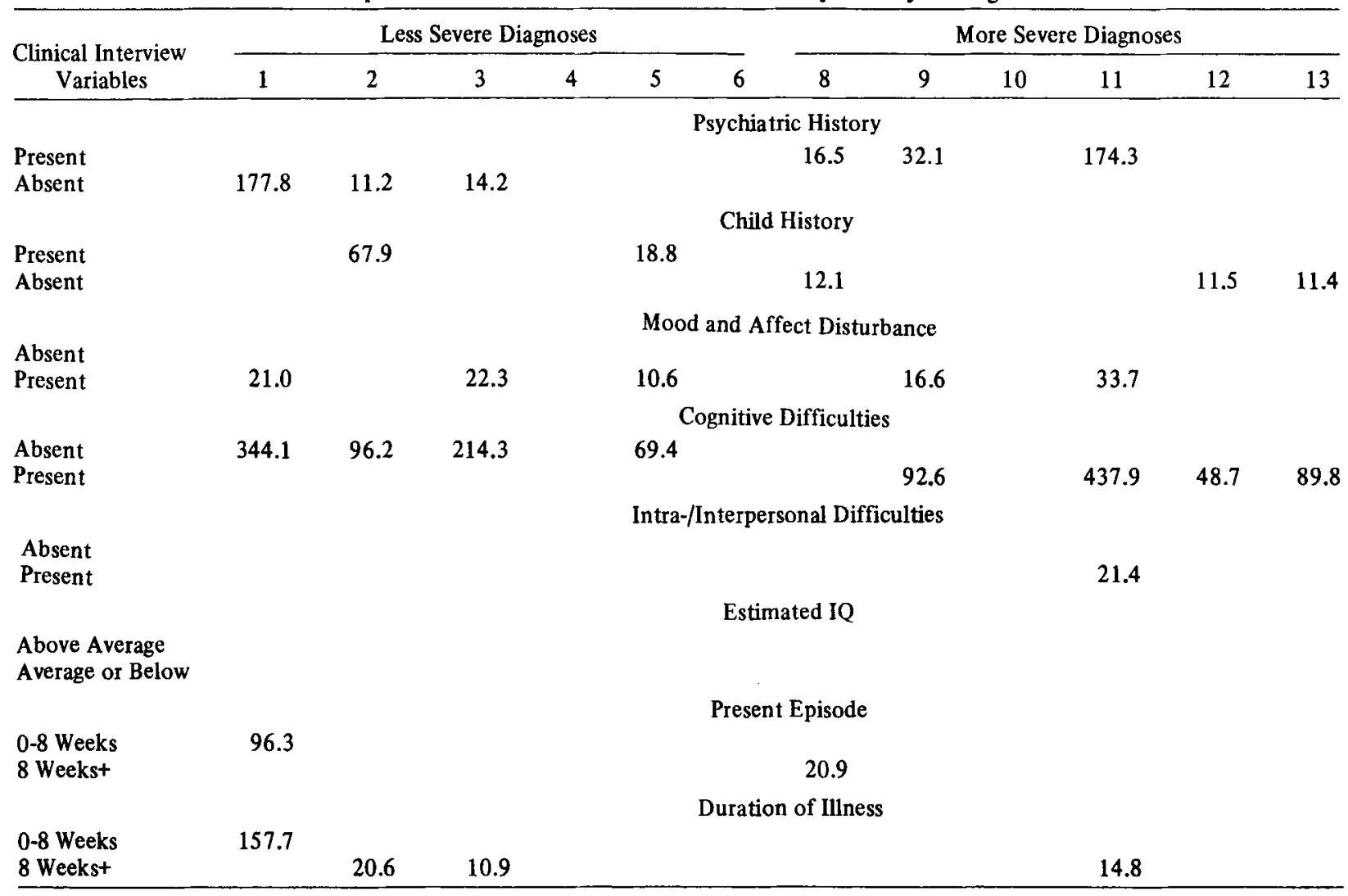

Note-All reported chi-square values are significant beyond the .001 level; all blanks indicate nonsignificant chi-square values. Diagnoses: (less severe) (1) transient situational disturbance $(N=704),(2)$ behavior disorder of childhood or adolescence $(N=203)$, (3) neurosis $(N=951)$, (4) sexual deviation $(N=3)$, (5) personality disorder $(N=451)$, (6) psychophysiological disorder $(N=38)$, (more severe) (8) alcoholism ( $N=342)$, (9) affective psychosis $(N=278)$, (10) mental retardation $(N=58)$, (11) nonaffective psychosis $(N=913),(12)$ nonpsychotic organic brain syndrome $(N=125),(13)$ psychotic organic brain syndrome $(N=208)$.

Table 3

Chi-Square Values for Clinical Judgment Variables by Severity of Diagnosis

\begin{tabular}{|c|c|c|c|c|c|c|c|c|c|c|c|c|}
\hline \multirow{2}{*}{$\begin{array}{c}\text { Clinical } \\
\text { Judgment } \\
\text { Variables }\end{array}$} & \multicolumn{6}{|c|}{ Less Severe Diagnoses } & \multicolumn{6}{|c|}{ More Severe Diagnoses } \\
\hline & 1 & 2 & 3 & 4 & 5 & 6 & 8 & 9 & 10 & 11 & 12 & 13 \\
\hline & \multicolumn{12}{|c|}{ Estimated Judgment Deficits } \\
\hline Yes & & & & & 13.6 & & & 43.8 & & 175.3 & 12.1 & 41.9 \\
\hline \multirow[t]{2}{*}{ No } & 53.5 & & & & & 18.2 & & & & & & \\
\hline & \multicolumn{12}{|c|}{ Estimated Potential Danger to Self } \\
\hline Yes & & & & & 11.4 & & & 59.4 & & 149.1 & & 25.6 \\
\hline \multirow[t]{2}{*}{ No } & 79.3 & & & & & 12.0 & & & & & & \\
\hline & \multicolumn{12}{|c|}{ Estimated Potential Danger to Others } \\
\hline Yes & & & & & & & & 25.8 & 10.5 & 356.3 & 27.7 & 37.6 \\
\hline \multirow[t]{2}{*}{ No } & 122.0 & & 147.1 & & & & & & & & & \\
\hline & \multicolumn{12}{|c|}{ Disposition } \\
\hline Outpatient & 409.8 & & 127.4 & & 26.6 & 18.9 & & & & & & \\
\hline Inpatient & & & & & & & 77.8 & 159.9 & & 483.1 & & 86.8 \\
\hline
\end{tabular}

Note-All reported chi-square values are significant beyond the .001 level; all blanks indicate nonsignificant chi-square values. Diagnoses: (less severe) (1) transient situational disturbance $(N=704)$, (2) behavior disorder of childhood or adolescence $(N=203)$, (3) neurosis $(N=951)$, (4) sexual deviation $(N=3),(5)$ personality disorder $(N=451)$, (6) psychophysiological disorder $(N=38)$, (more severe) (8) alcoholism $(N=342)$, (9) affective psychosis $(N=278)$, (10) mental retardation $(N=58)$, (11) nonaffective psychosis $(N=913)$, (12) nonpsychotic organic brain syndrome $(N=125)$, (13) psychotic organic brain syndrome $(N=208)$. 
Table 4

Discriminant Function Data Parameters of Discriminant Functions

\begin{tabular}{|c|c|c|c|c|c|c|c|c|}
\hline $\begin{array}{c}\text { Functions } \\
\text { Derived }\end{array}$ & $\begin{array}{l}\text { Wilks' } \\
\text { Lambda }\end{array}$ & $\begin{array}{c}\text { Chi } \\
\text { Square }\end{array}$ & $\begin{array}{r}\mathrm{Si} \\
\mathrm{c}\end{array}$ & $\begin{array}{l}\text { Signifi- } \\
\text { cance }\end{array}$ & $\begin{array}{l}\text { Eigen } \\
\text { Value }\end{array}$ & $\begin{array}{c}\text { Relative } \\
\text { Percentage }\end{array}$ & \multicolumn{2}{|c|}{$\begin{array}{l}\text { Canonical } \\
\text { Correlation }\end{array}$} \\
\hline 1 & .32 & 4650.45 & 123 & .001 & 1.19 & 74.32 & \multicolumn{2}{|l|}{.74} \\
\hline 2 & .69 & 1494.52 & 80 & .001 & .27 & 16.65 & \multicolumn{2}{|l|}{.46} \\
\hline 3 & .87 & 543.47 & 39 & .001 & .14 & 9.03 & \multicolumn{2}{|l|}{.36} \\
\hline \multicolumn{9}{|c|}{ Components and Coefficients of Discriminant Functions } \\
\hline \multicolumn{2}{|c|}{ Function 1} & & \multicolumn{2}{|l|}{ Function 2} & \multicolumn{4}{|c|}{ Function 3} \\
\hline \multirow{8}{*}{$\begin{array}{l}\text { Delusions } \\
\text { Cognitive Dif }\end{array}$} & & .62 & Absence of Delusions & .85 & Absen & Disorientation & & .90 \\
\hline & ulties not WNL & .52 & Alcohol Abuse & .75 & Alcoho & & & .83 \\
\hline & & & Disorientation & .58 & Absen & Loss of Recen & emory & .82 \\
\hline & & & Loss of Immediate Recall & .57 & Dissoc & Depersonaliz & & .74 \\
\hline & & & Absence of Flight of Ideas & .57 & Absen & Loss of Immed & e Recall & .72 \\
\hline & & & Confabulation & .55 & Absen & Confabulation & & .65 \\
\hline & & & Older Age $(30+)$ & .41 & & Problems & & .51 \\
\hline & & & Male Sex & .40 & & & & \\
\hline
\end{tabular}

Table 5

Parameters of Diagnostic Groups in Discriminant Analysis

\begin{tabular}{lccccc}
\hline & \multicolumn{5}{c}{ Diagnostic Group } \\
\cline { 2 - 5 } \multicolumn{1}{c}{ Parameter } & 1 & 2 & 3 & 4 \\
\hline A Priori Probability of Assignment & .41 & .22 & .29 & .08 \\
& \multicolumn{5}{c}{ Group Centroids } \\
Function 1 & -.72 & -.26 & .95 & .84 \\
Function 2 & -.24 & -.59 & $\cdots .36$ & .93 \\
Function 3 & -.18 & .47 & .13 & -.85 \\
\hline
\end{tabular}

Note-Diagnostic groups: (1) neuroses ( $N=1,642)$, (2) personality disorders $(N=892)$, (3) functional psychoses $(N=1,187)$, (4) organic disorders $(N=333)$. Total $N=4,054$. Behavior disorder of childhood or adolescence, sexual deviation, psychophysiological disorder, and mental retardation were excluded from the above groups. Neurosis includes transient situational disturbance and neurosis. Personality disorders include personality disorder, drug dependence, and alcoholism. Functional psychoses include affective and nonaffective psychoses. Organic disorders include nonpsychotic and psychotic organic brain syndromes.

that the demographic variables of age and sex and the clinical interview variables of cognitive difficulties, alcohol abuse, and intra/interpersonal difficulties contributed in a significant manner to allow differentiation among the four diagnostic groups. However, clinical judgment variables did not appear to be a significant part of the cumulative effects of variables on diagnosis.

Results of the analysis phase indicated that three discriminant functions were derived (see Table 4), the maximum allowed under programmed conditions of statistical significance required to describe and separate the four diagnostic groups. Group centroids for the three discriminant functions and four diagnostic groups are listed in Table 5. Separation of the diagnostic groups using discriminant Functions 1 and 2 is depicted in Figure 1. The figure shows that Function 1 (horizontal) most clearly separated the neuroses and personality disorders from the functional psychoses and organic disorders, and the neuroses from the personality disorders to a lesser extent. Although Function 3 was not included as an axis in the figure, its greatest utility was in separating personality disorders from organic disorders.

Results of the prediction phase are shown in Table 6. Utilizing the three derived discriminant functions, $68.2 \%$ of the 4,054 patients from the four diagnostic groups were correctly classified into their respective groups, with proportions of correct prediction ranging from $83.3 \%$ (neuroses) to $45.2 \%$ (personality disorders). Thus, the three discriminant functions were more successful in correctly assigning neurotic and functionally psychotic patients and less successful in assigning personality disorder and organic disorder patients to

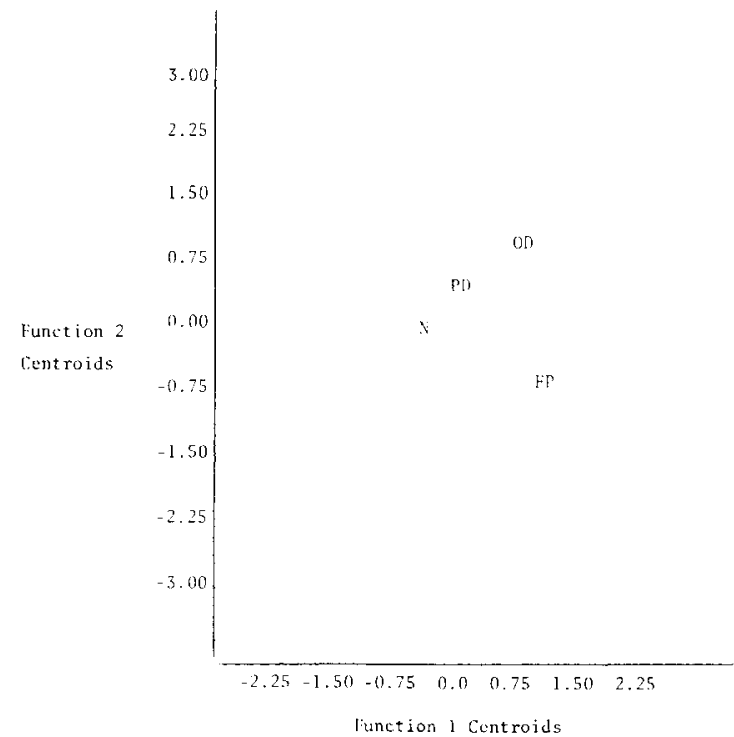

Figure 1. Plot of discriminant Functions 1 and 2 for each diagnostic group. $N=$ neuroses, $P D=$ personality disorders, $\mathrm{FP}=$ functional psychoses, $\mathrm{OD}=$ organic disorders. 
Table 6

Prediction Results of Discriminant Analysis

\begin{tabular}{|c|c|c|c|c|c|c|c|c|c|c|c|c|c|c|c|c|c|}
\hline \multirow{3}{*}{$\begin{array}{l}\text { Observed Group } \\
\text { Membership }\end{array}$} & \multirow[b]{3}{*}{$\mathrm{N}$} & \multicolumn{16}{|c|}{ Predicted Group Membership } \\
\hline & & \multicolumn{4}{|c|}{ Neuroses } & \multicolumn{4}{|c|}{ Personality Disorders } & \multicolumn{4}{|c|}{ Functional Psychoses } & \multicolumn{4}{|c|}{ Organic Disorders } \\
\hline & & $\mathrm{P} 1$ & $\mathbf{P 2}$ & AN & $\mathrm{AP}$ & P1 & P2 & AN & AP & $\mathbf{P 1}$ & $\mathbf{P} 2$ & AN & AP & P1 & P2 & AN & $\mathrm{AP}$ \\
\hline Neuroses & 1662 & .41 & .73 & 1368 & 83.3 & & 24 & 172 & 10.5 & & .07 & 83 & 5.1 & & .06 & 19 & 1.2 \\
\hline Personality Disorders & 892 & & 19 & 356 & 39.9 & .22 & .55 & 403 & 45.2 & & .08 & 89 & 10.0 & & .14 & 44 & \\
\hline Functional Psychoses & 1176 & & .07 & 137 & 11.5 & & .15 & 109 & 9.2 & .29 & .75 & 838 & 70.6 & & .32 & 103 & 8.7 \\
\hline Organic Disorders & 324 & & .01 & 25 & 7.5 & & .06 & 47 & 14.1 & & .09 & 105 & 31.5 & .08 & .48 & 156 & 41.8 \\
\hline
\end{tabular}

Note-PI = base rate (a priori) probability of group assignment. $P 2=$ conditional probability of group assignment using discriminant functions. $A N=$ number assigned. $A P=$ percentage assigned.

their respective diagnostic groups. The probability of correct assignment increased demonstrably over chance assignment for all diagnostic groups when the discriminant functions were used.

Findings of the present study suggested a model for a clinical judgment process in which the clinician takes note of the patient's demographic features, searches for the presence of some clinical interview variables in the patient and notes the absence of others, and assesses the presence or absence of the patient's potential danger to himself/herself and to others. This clinical judgment process culminates in the diagnosis, the severity of which is differentially determined by the clinician's impression of characteristics perceived in the patient during the process.

On the basis of this presence/absence approach, hypotheses concerning the nature and seriousness of the patient's emergency, the patient's treatment needs, and probable response to different treatments available are apparently generated, tested, and accepted or rejected. Such a hypothesis generation/testing approach resembles clinical judgment models suggested by previous research (Lazare, 1976; Roberts, 1978; American Psychiatric Association, Note 4).

The PIR provided the structure necessary for improving clinical judgment over chance levels and for organizing the interview data to facilitate investigation of the clinical judgment process. Findings regarding clinician agreement upon severity of diagnosis, significance of the presence and absence of certain variables or symptoms as related to diagnosis, and rates of correct prediction of diagnostic groups support earlier research indicating the role of standardized formats in the evaluation of psychopathology (Climent, Plutchik, Estrade Gaviria, \& Arevalo, 1974; Endicott \& Spitzer, 1972; Luborsky \& Bachrach, 1974; Potkay, 1973).

Discriminant analysis results confirm the utility of using such statistics in defining symptom clusters to improve psychiatric diagnostic procedures (Newmark et al., 1976; Yusin et al., 1974). These results seem especially important in confirming the validity of the discriminant analysis approach to the diagnostic process. By deriving groups of symptoms based on demographic and clinical interview characteristics of patients, the ability to correctly diagnose neurotic and psychotic patients was improved over predicted base-rate levels. Also, discriminant analysis distinctly separated the psychoses and organic disorders from the neuroses and personality disorders, and the psychoses from the organic disorders. Finally, the discriminant analysis results appear promising in confirming the validity of a technique combining clinical judgment and computer assistance in improving the accuracy and appropriate ness of diagnostic and dispositional procedures. Such results could be used in a decision-tree model (Endicott $\&$ Spitzer, 1972) by the clinician for diagnostic purposes, improving the reliability of diagnosis without restricting the clinician's role in the process.

\section{REPEAT VISIT PHENOMENON IN THE PER}

In reviewing the above data, we noted a substantial number of visits were made by patients who had previously visited the emergency room. Our interest in this phenomenon prompted an investigation into recidivism in the PER (Munves, 1977).

A review of the available literature on psychiatric emergencies reveals only 10 studies that mention the repeat visit phenomenon. The proportion of patients reported to be repeaters ranges from $7 \%$ to $11 \%$, with a mean value of $9 \%$, for studies that cover a 1 -year period (Miller, 1968; Ungerleider, 1960). None of the studies that cover a 1-year period of time or longer reports the proportion of patients who repeat. The proportion of repeat visits for the studies reviewed that cover a 6-month period or less ranges from $14 \%$ to $18 \%$, with a mean value of $16 \%$ (Miller, 1968; Schwartz, Weiss, \& Miner, 1972 ), and the proportion of repeat visits ranges from $13 \%$ to $38 \%$, with a mean value of $25.2 \%$ for studies covering a 1-year period (Atkins, 1967; Chafetz, 1965; Freeman \& Roy, 1971; Muller et al., 1967; Straker, Yung, \& Weiss, 1971). In addition to indicating the amount of utilization associated with emergency room recidivism, these findings reflect a considerable degree of human suffering.

Nonetheless, little is known about repeaters, as most 
of the studies cited above only alluded to the repeat visit phenomenon. Some of the studies, however, included analyses that indicate that repeaters may have a profile that is distinct from that of the one-time visitor. Repeaters may be more likely to have a previous psychiatric history (Freeman \& Roy, 1971; Miller, 1968; Ungerleider, 1960). They may be more socially isolated (Miller, 1968; Raphling \& Lion, 1970) and more likely to be separated, divorced, or widowed (Miller, 1968). Miller (1968) studied 183 patients who made a total of 224 contacts during a 6-month period. In this investigation, almost all of the repeaters were female $(90 \%)$, and more than half of them were no longer with their spouses (56\%). A more recent study (Schwartz et al., 1972) compared the marital status of single visit and repeat patients and found that marital status did not differ appreciably between the groups. However, there have been consistent findings that suggest repeaters differ from nonrepeaters in terms of their diagnoses. Raphling and Lion (1970) studied 15 patients who each visited the emergency room from 7 to 30 times in 1 year. They considered each of these patients to be borderline personalities. Similarly, Schwartz et al. (1972) found that repeaters were more likely to be diagnosed as having personality disorders with chronic pathology, including alcohol and drug dependence, and to be hospitalized.

The present study could be characterized as a largescale exploratory effort that was stimulated by the preliminary work of Schwartz et al. (1972). The purpose of this study is to describe the repeat visit phenomenon over time and to ascertain its correlates.

The setting for the present study was the PER of Dallas County's Parkland Memorial Hospital. Patients referred to the PER were evaluated using the PIR. The records of all patients who had visited the PER during the 21-month period from November 1, 1974, to July 31,1976 , were screened so as to exclude all patients who had previously visited the PER. There remained a sample of 3,824 first-visit patients for the period selected for study.

This total sample was divided into two cohorts, so as to make it possible to validate correlates of repeat behavior. Cohort $1(\mathrm{~N}=2,561)$ was composed of all patients who had visited the PER for the first time during the 6-month period from November 1, 1974, to April 30, 1975. Repeat visit data were collected for each Cohort 1 subject for the 12 months (360 days) following his/her initial visit. Cohort $2(\mathrm{~N}=1,263)$ was composed of all patients who had visited the PER for the first time during the 3-month period from May 1, 1975, to July 31,1975 . Thus, repeat visit data were available for each Cohort 2 subject for the 12 months (360 days) following his/her initial visit. Additional subgroupings were formed from this total sample to investigate correlates of various levels of repeating.

For purposes of data analysis, the date of a patient's first visit was treated as Day 0, and the time of each subsequent visit, if any, was expressed as the number of days after Day 0. In this way, it was ensured that every patient was followed for an equivalent length of time. Moreover, it was then possible to compare patients in terms of their history (i.e., the length of time that elapsed between their initial visit and their respective repeat visits). This treatment of the data made it possible to generate any number of subgroups for each cohort distinguished by the number of visits made by the patients within specified time periods from their initial visits.

Two general types of data analysis were employed to analyze the data gathered in this study. First, descriptive statistics such as frequency distributions and proportions were used to describe the repeat visit phenomenon over time. This analysis was also appropriate to determine the levels of the dependent variable, namely, repeating.

Second, cross-tabulations were performed in order to assess time and the selected demographic, visit, clinical, and outcome variables, taken individually, as predictors of repeating. These measures were employed only when the independent variables were conceived as nominal level. These included chi square, corrected when appropriate, and the uncertainty coefficient. Chi square was employed to assess whether a systematic relationship existed between a given independent variable and the presence or absence of repeats. The asymmetric uncertainty coefficient is designated for nominallevel variables and is a measure of strength of relationship. This statistic was employed to ascertain the proportion by which "uncertainty" in the dependent variable was reduced by knowledge of the independent variable. The maximum value for the uncertainty coefficient is 1.0 , which denotes the complete elimination of uncertainty.

Repeating was always treated as a nominal-level variable, inasmuch as the patients were subgrouped in terms of their visit histories. It should be noted that all cases with relevant missing values were excluded from the analysis of independent variables in order to enhance validity. Additionally, the level of significance for all analyses involving PIR data for Cohorts 1 and 2 was established at .001 .

The data of Cohort $1(\mathrm{~N}=2,561)$ were used to describe the frequency distribution of repeat visits over cumulative time periods. Table 7 is a summary of the utilization frequencies by follow-up periods. The time periods as shown in this table are cumulative (e.g., the 360-day period includes all earlier periods), whereas the classes for number of repeats are mutually exclusive. The first row of the table, for example, shows that $90.3 \%$ of the patients did not return for a second or additional visits within the first 90-day period. By the end of the 360 -day period, $82.3 \%$ of the patients had 
Table 7

Frequency (f) and Percent (P) of Cohort 1 Patients $(\mathrm{N}=2,561)$ by Number of Repeats (R) and by Follow-Up Period

\begin{tabular}{|c|c|c|c|c|c|c|c|c|}
\hline \multirow[b]{3}{*}{$\mathbf{R}$} & \multicolumn{8}{|c|}{ Follow-Up Period } \\
\hline & \multicolumn{2}{|c|}{90 Days } & \multicolumn{2}{|c|}{180 Days } & \multicolumn{2}{|c|}{270 Days } & \multicolumn{2}{|c|}{360 Days } \\
\hline & $\mathrm{f}$ & $\mathrm{P}$ & $\mathrm{f}$ & $\mathbf{P}$ & f & $\mathrm{P}$ & $\mathrm{f}$ & $\mathbf{P}$ \\
\hline 0 & 2310 & 90.3 & 2222 & 86.7 & 2152 & 84.1 & 2108 & 82.3 \\
\hline 1 & 213 & 8.3 & 260 & 10.2 & 298 & 11.6 & 315 & 12.3 \\
\hline 2 & 32 & 1.2 & 57 & 2.2 & 77 & 3.0 & 93 & 3.6 \\
\hline 3* & 6 & .2 & 22 & .9 & 34 & 1.3 & 45 & 1.8 \\
\hline
\end{tabular}

*Three or more.

Table 8

Repeat Visits in Each Cumulative Follow-Up Period for Cohort $1(\mathrm{~N}=2,561)$

\begin{tabular}{cccc}
$\begin{array}{c}\text { Follow-Up } \\
\text { Period }\end{array}$ & $\begin{array}{c}\text { Total } \\
\text { Visits }\end{array}$ & Repeats & $\begin{array}{c}\text { Percent } \\
\text { Repeats }\end{array}$ \\
\hline 90 Days & 2856 & 295 & 10.3 \\
180 Days & 3006 & 445 & 14.8 \\
270 Days & 3129 & 568 & 18.2 \\
360 Days & 3223 & 662 & 20.5 \\
\hline
\end{tabular}

not returned, and $17.7 \%$ had repeated one or more times. For each cumulative period, the frequency distributions are extremely positively skewed, in fact, $\mathrm{J}$-shaped. Most patients did not repeat, and only a small minority had three or more repeats. Although the percent of patients having one or more repeats remained fairly small, these patients accounted for a substantial percentage of the total number of the visits in each follow-up period, as may be seen in Table 8.

If we classify a patient who has one or more repeats as a "repeater" and one who has no repeats as a "nonrepeater," then we may ask how many patients entered the status of a (new) repeater in each successive 90-day time period. The data were as follows: first 90 days, 251 (9.7\%); second 90 days, 88 (3.4\%); third 90 days, $70(2.7 \%)$; and fourth 90 days, $44(1.7 \%)$. Thus the frequency and percent of patients who first became repeaters progressively decreased with successive time periods in what appears to be a negatively accelerated decreasing function of time. These same data may also be considered from a slightly different point of view. How did the probability of first becoming a repeater vary as a function of how long a patient had deferred a repeat visit? For each successive time period, this probability may be estimated by dividing the number who entered repeat status during that period by the maximum number who at the beginning of the period could have become repeaters (i.e., who were nonrepeaters at the beginning of the period). The data for these conditional probabilities for successive time periods were as follows: first 90 days, .097; second 90 days, .038; third 90 days, .032; and fourth 90 days, .020. Thus, the longer that a patient remained a nonrepeater, the less likely he was to make one or more repeat visits within the next 90 days.
A similar analysis based on the combined sample $(\mathrm{N}=3,824)$ was done using 30 -day periods. Here, the conditional probabilities for becoming a repeater in the next 30-day period, given that a patient was a nonrepeater at the beginning of the period, were as follows: first period, .060; second period, .019; third period, .015 ; fourth period, .011 ; fifth period, .012; and sixth period, .011. Here, it appears that the most dramatic change in probability occurs from the 1 st to the 2 nd month. In other words, if a patient has not repeated in the 1st month, the probability of repeating substantially declines. Indeed, of all patients who repeated sometime within the first 6 months (466), 228 (or 48.9\%) did so within the 1 st month.

Is there any relationship between repeating in one time period and repeating in the next time period? To answer this question, each subject in the combined sample was classified as repeating vs. not repeating in the first 90-day period and then classified as repeating vs. not repeating in the second 90-day period. The findings appear in Table 9.

The resulting chi square was highly significant and indicates that there was a nonchance relationship. The relative frequency of repeating in the second 90 days, given that one had repeated in the first 90 days, was $60 / 351=.171$; but if a patient had not repeated in the first 90 days, the corresponding relative frequency was only $115 / 3,473=.033$. Thus, the findings indicate a relationship between repeat-nonrepeat behavior in one period and similar behavior in another time period. This finding suggests that individual differences in the behavior under study are not explained by a purely random process.

The results are viewed as important in that they add to the sparse literature on the repeat visit phenomenon in general, as well as to the understanding of this phenomenon in the PER in particular. The present findings with respect to the magnitude of the repeat visit phenomenon are consistent with those of earlier reported research.

As had been indicated, the results suggest that there are at least two distinct subgroups of repeaters that can be distinguished on the basis of their utilization patterns, one group being composed of patients who repeat soon after their initial visit and the second group consisting of patients who repeat after a longer time has elapsed from

Table 9

Relation Between Repeating in the First 90-Day Period and Repeating in the Second 90-Day Period

\begin{tabular}{lccr} 
& \multicolumn{3}{c}{ Second 90-Day Period } \\
\cline { 2 - 4 } $\begin{array}{c}\text { First 90-Day } \\
\text { Period }\end{array}$ & Repeating & $\begin{array}{c}\text { Not } \\
\text { Repeating }\end{array}$ & Total \\
\hline Repeating & 60 & 291 & 351 \\
Not Repeating & 115 & 3358 & 3473 \\
Total & 175 & 3649 & 3824 \\
\hline
\end{tabular}

Note $-x^{2}=133.06(p \leqslant .001)$. 
their initial visit. This finding seems to confirm the notion of earlier investigators that there might be subgroups of repeaters who differ in terms of the frequency with which they visit the PER (Schwartz et al., 1972).

\section{PATIENT CHARACTERISTICS RELATED TO TREATMENT SUCCESS IN SHORT-TERM PSYCHIATRIC HOSPITALIZATION}

Since the PER serves as the point of entrance to the inpatient psychiatric unit, we were afforded the opportunity to explore the patient characteristics related to successful treatment of such a unit (Hibberd, 1980). We noted that there has been an increasing trend toward the use of short-term psychiatric hospitalization for those in need of residential treatment. Short-term inpatient units have been defined (Maxmen, Tucker, \& LeBow, 1974) as having an expected length of stay for patients of less than 21 days. Such programs typically aim at treating the patient's acute crisis rather than providing rehabilitative treatment or resolving an underlying personality-based disorder.

The suitability of treatment on short-term wards for all patients in need of psychiatric hospitalization has been questioned (Rabiner \& Lurie, 1974; Wing, 1978). In our own experience in a short-term psychiatric unit in an urban county hospital, we have noted that a minority of patients admitted to the unit do not appear to be suited for this type of treatment. Some patients do not recover rapidly enough to complete their treatment on a short-term unit and must be transferred to other facilities. Others complete their treatment on the short-term unit but require a longer period of hospitalization than the unit is designed to provide. Since clinical practitioners now frequently have the choice of referring patients in need of hospitalization to short-term or longer term psychiatric facilities, it would be desirable to identify patient characteristics associated with successful short-term treatment.

The present study examined data collected in the normal course of assessment and referral in a hospital PER for patients subsequently referred to short-term inpatient treatment. By comparing data collected in the emergency room with patients' subsequent hospital treatment outcome, the study was intended to identify patient characteristics that are associated with successful or unsuccessful short-term inpatient treatment.

Again, the setting for the present study was Parkland Memorial Hospital, which contains an 18-bed inpatient psychiatric ward designed to provide acute care to adults and older adolescents. Patients treated on the inpatient unit are usually admitted through the hospital's PER, in which they have typically been preselected by psychiatric personnel as likely to benefit from shortterm inpatient care. The unit is staffed by a psychiatrist, a psychologist, psychiatric residents, psychology interns, a social worker, psychiatric nurses, and aides. Since Parkland is affiliated with the University of Texas Health Science Center, the psychiatric unit serves as a training facility for various types of mental health professionals. Patients are treated using various combinations of individual psychotherapy, family counseling, group psychotherapy, occupational therapy, medications, and somatic treatments. The treatment goals on the inpatient psychiatric unit include extensive assess. ment of the patient's difficulties, intervention in the crisis in which the patient is involved, and stabilization of the patient's functioning. Treatment is aimed at improving the patient's biological, psychological, and social functioning to the level at which he/she typically operated in the past. There is generally little emphasis on the patient's achieving substantial dynamic insight or structural psychological change. An attempt is made to complete inpatient treatment within 2 or 3 weeks after admission, and the median length of stay on the unit during the period in which data were collected was 11 days.

Clinical and demographic features of patients were explored as potentially related to treatment outcome. These features had been evaluated in Parkland's PER, just prior to inpatient admission, during the normal assessment and referral process. All patient assessment information, including a clinical formulation and treatment recommendation, was recorded by emergency room personnel on the PIR. From this record, 18 demographic variables and 156 clinical variables were examined for purposes of this study. Clinical features were coded as present or absent.

Treatment outcome was assessed in terms of length of stay on the inpatient unit ( 21 days or less vs. over 21 days) and disposition upon discharge, in four outcome groups: (1) short stay/discharge home, (2) short stay/transfer to another psychiatric hospital, (3) long stay/discharge home, (4) long stay/transfer to another psychiatric hospital.

Data were reviewed for all consecutive admissions to the psychiatric inpatient unit over a 2-year period for patients who had been (1) referred from the PER, (2) discharged with medical advice, (3) either discharged home or transferred to another psychiatric hospital, and (3) not readmitted to the inpatient unit within 30 days. In all, 612 patients met the criteria for inclusion in the study. Contingency table data were analyzed, comparing each demographic or clinical variable to membership in outcome groups, using the log likelihood ratio chi square (Bliss, 1967). A rigorous criterion of significance $(p<.01)$ was employed due to the large number of variables investigated.

A substantial number of clinical variables were found to be related to treatment outcome when all four outcome groups were compared (see Table 10). For 20 of the 21 clinical variables thus found to be related to 
Table 10

Percentage of Patients Showing Clinical Features in Each Outcome Group

\begin{tabular}{|c|c|c|c|c|c|}
\hline \multirow[b]{2}{*}{ Clinical Feature } & \multirow[b]{2}{*}{$\mathrm{p}<$} & \multicolumn{4}{|c|}{ Outcome Group } \\
\hline & & $\begin{array}{c}\mathrm{SH} \\
(\mathrm{N}=448) \\
\end{array}$ & $\begin{array}{c}\text { ST } \\
(N=49)\end{array}$ & $\begin{array}{c}\text { LH } \\
(N=99)\end{array}$ & $\begin{array}{c}\text { LT } \\
(\mathrm{N}=16)\end{array}$ \\
\hline & \multicolumn{5}{|c|}{ Variables Positively Related to Successful Outcome } \\
\hline Diagnosis of Neurosis & .0001 & 41 & $20^{*}$ & $18 \dagger$ & $0 \dagger$ \\
\hline Suicidal Thoughts-Recent & .0001 & 48 & $24^{*}$ & $24 \dagger$ & 31 \\
\hline Depressed Mood & .0001 & 70 & $41 \dagger$ & $52+$ & 44 \\
\hline Suicidal Thoughts-Any History & .0001 & 51 & $29^{*}$ & $27 \dagger$ & 31 \\
\hline Cognitive Difficulties Within Normal Limits & .0001 & 26 & $8^{*}$ & $10 \dagger$ & 12 \\
\hline Alcohol Abuse-Recent & .0001 & 23 & 20 & $8+$ & $0^{*}$ \\
\hline Suicidal Behavior-Recent & .001 & 30 & 14 & $14 \dagger$ & 12 \\
\hline Suicidal Behavior-Any History & .01 & 35 & $16^{*}$ & 22 & 12 \\
\hline Sedative Abuse-Any History & .01 & 19 & 10 & $6 *$ & 6 \\
\hline Sedative Abuse-Recent & .01 & 16 & 8 & $5^{*}$ & 12 \\
\hline Marital Difficulties & .02 & 35 & $16^{*}$ & 24 & 31 \\
\hline Alcohol Abuse-Any History & .03 & 29 & 29 & $15^{*}$ & 18 \\
\hline Two or More Drugs Abused & .03 & 15 & 8 & $5^{*}$ & 12 \\
\hline Soft Speech & .04 & 31 & $12^{*}$ & 31 & 31 \\
\hline Hypoactive Motor Behavior & .05 & 41 & $22 *$ & 43 & 31 \\
\hline \multirow[t]{2}{*}{ Dissociation/Depersonalization } & .02 & 10 & $0^{*}$ & 10 & 12 \\
\hline & \multicolumn{5}{|c|}{ Variables Negatively Related to Successful Outcome } \\
\hline Diagnosis of Nonaffective Psychosis & .0001 & 20 & $41^{*}$ & $48 \dagger$ & $62 \dagger$ \\
\hline Suspicious Attitude in Interview & .0001 & 26 & $55 \dagger$ & $41^{*}$ & 56 \\
\hline Loose Associations & .0001 & 15 & 24 & $35 \dagger$ & 38 \\
\hline Hostile Attitude in Interview & .01 & 15 & $34^{*}$ & 18 & $44^{*}$ \\
\hline Delusions & .001 & 24 & $43^{*}$ & $38^{*}$ & 50 \\
\hline Interpersonal Suspiciousness/Hostility & .001 & 27 & 33 & $47 \dagger$ & 50 \\
\hline Two or More Cognitive Symptoms Present & .001 & 40 & 52 & $57 \dagger$ & 69 \\
\hline Loud Speech & .01 & 5 & 10 & $16 \dagger$ & 0 \\
\hline Flight of Ideas & .01 & 9 & $26^{*}$ & 18 & 19 \\
\hline Hallucinations & .01 & 19 & 26 & 24 & $50^{*}$ \\
\hline Inappropriate Affect & .01 & 19 & 35 & 31 & 38 \\
\hline Circumstantiality/Tangentiality & .03 & 28 & 30 & $42^{*}$ & 50 \\
\hline Outpatient Chemotherapy & .04 & 12 & 14 & $23^{*}$ & 6 \\
\hline Abstraction Deficit & .05 & 23 & 20 & $36^{*}$ & 25 \\
\hline
\end{tabular}

Note-SH = short-stay/home group, ST = short-stay/transfer group, LH=long-stay/home group, LT=long-stay/transfer group. Loglikelihood ratio chi square was used for all significance tests.

${ }^{*} p<.01$ for comparison with short-stay home group.

tp $<.001$ for comparison with short-stay home group.

outcome, the short stay/discharge home group, the most successful outcome group from a clinical or administrative point of view, differed from each of the other groups in a consistent direction. Thus it was possible to characterize this optimum outcome group in terms of the relative presence or absence of the clinical features noted. Patients in the most successful group were more likely to have a neurotic diagnosis, depressed mood, suicidal thoughts or behavior, alcohol abuse, and sedaitive abuse. Patients in this group were less likely to have a diagnosis of nonaffective psychosis, suspiciousness, hostility, inappropriate affect, and cognitive symptoms, including loose associations, flight of ideas, delusions, and hallucinations.

No demographic variables showed a consistent as well as significant relationship to successful treatment outcome (see Table 11). Sex was related to membership in one or the other of the discharge home groups (more females) vs. the transfer groups (more males, $p<.001$ ). Marital status showed near significance $(p<.05)$ in a similar pattern, with individuals who had never married occurring more frequently in the transfer groups.
Table 11

Percentage of Patients Showing Demographic Features in Each Outcome Group

\begin{tabular}{lcccc}
\hline & \multicolumn{4}{c}{ Outcome Group } \\
\cline { 2 - 5 } \multicolumn{1}{c}{ Demographic Feature } & SH & ST & LH & LT \\
\hline Male & \multicolumn{4}{c}{ Sex $(\mathrm{p}<.001)$} \\
Female & 33 & 57 & 27 & 50 \\
& 67 & 45 & 73 & 50 \\
Single, Never Married & Marital Status (p $<.05)$ \\
Married, Living with Spouse & 25 & 50 & 27 & 38 \\
Divorced, Widowed, or Separated & 38 & 25 & 34 & 38 \\
& 37 & 25 & 39 & 25 \\
& Emergency & Room Arrival \\
Midnight-8:00 a.m. & \multicolumn{4}{c}{ Time (p $<.05)$} \\
8:00 a.m.-4:00 p.m. & 16 & 12 & 5 & 0 \\
4:00 p.m.-Midnight & 47 & 51 & 47 & 44 \\
\hline
\end{tabular}

Note-SH = short-stay/home group $(n=448), S T=$ short-stay) transfer group $(n=49), L H=$ long-stay/home group $(n=99)$, $L T=$ long-stay $/$ transfer group $(n=16)$. Table includes only those variables that were associated with differences among the fout outcome groups at the $p<.05$ level of significance. Log. likelihood ratio chi square was used for all significance tests. 
Patients' arrival time in the emergency room showed a marginally significant relationship $(\mathrm{p}<.05)$ to successful treatment outcome, with patients in the optimum short stay/discharge home group being relatively more likely to have arrived late at night and less likely to have arrived in the evening than members of the other groups.

None of the clinical or demographic variables examined, taken individually, showed a strong degree of relationship with the outcome measures. The highest correlation observed was between diagnosis of nonaffective psychosis and outcome group membership (Cramer's V $=.270$ ).

Two explanations are suggested to account for the clinical predictors found to be related to treatment success in these data. The clinical features associated with success may represent milder patterns of psychopathology in patients who required hospitalization, but who were not as severely disturbed as the unsuccessful patients. For this explanation, treatment success could be simply a function of severity of psychopathology. Alternatively, the clinical features associated with successful treatment outcome may be indicators of acute, subjectively experienced distress in patients who are experiencing a crisis situation in their lives. Such patients might be expected to respond more successfully to crisis-oriented short-term hospitalization than those who are either not in a crisis situation at the time of hospitalization or who do not recognize or acknowledge distress. The latter group of unsuccessfully treated patients might be using psychotic or externalizing symptoms (e.g., hostility and suspiciousness) to ward off recognition or personal responsibility for the environmental difficulties leading to hospitalization.

The relative paucity of demographic features associated with short-term inpatient treatment outcome was somewhat surprising and provides negative evidence in support of the idea that this type of treatment may be equally suitable for a broad cross-section of individuals, regardless of age, race, education, and socioeconomic status. Further research is required to confirm this impression. The observed relationships between transfer prior to completion of treatment and male sex and never-married status may perhaps be explained in terms of these individuals' being less socially involved and responsive to others and, hence, more likely to be transferred. Emergency room arrival time may be related to the acuteness of the crisis for which hospitalization occurred, with patients arriving late at night having more acute crises and thus better treatment outcome.

The modest magnitude of correlations observed between clinical and demographic characteristics and treatment outcome raises the possibility that other factors were involved in influencing the outcome indexes employed. Our clinical observations suggest that motivational features of patients, including attitudes and expectancies, may also influence treatment outcome on this type of inpatient unit. Further research is currently in progress to explore these aspects of patients as outcome predictors. The present study was also limited in scope in that only length of stay and disposition upon discharge were examined as measures of treatment outcome. Further research is under way to determine whether the clinical predictors identified would also be related to more direct assessments of patient change, such as measures of clinical and social improvement upon discharge.

\section{A COMPARATIVE EVALUATION OF 162 INHALANT USERS}

In addition to major research efforts evaluating large segments of the emergency room population, the system's flexibility enabled us to pinpoint specific target populations for study. One such group investigated consisted of inhalant users requiring psychiatric intervention.

Two recent book-length publications have reviewed ongoing international inhalant research (Contreras \& Perez, 1977) and examined the current state of the art (Sharp \& Brehm, Note 5). Clearly, the volunatry inhalation (sniffing) of volatile solvents has continued to be a public health problem since it reached notoriety in the 1960s.

Much concern has recently been expressed regarding the clinical effects, particularly the behavioral consequences, of sniffing (Vargas, Note 6). The literature in this regard has typically been sparse and anecdotal, characterized by small sample studies without controls (Korman, Note 7).

It might be argued that if there are serious psychiatric consequences to solvent use, particularly those of an acute nature, a significant proportion of individuals exhibiting these problems should find their way to PERs. In such a setting, they can be studied in contrast to noninhalant drug users, as well as to non-drug-using psychiatric casualties generally. The present investigation attempted to do this.

During the 24 months of gathering the PIR data base, a total of 162 inhalant users were seen in the PER. These individuals reported a wide range of drug involvement other than inhalant use, ranging from no other drugs to a large number of different drugs used extensively for a relatively long time. Drug use is defined here as any incidence (whether on a short-term, long. term, or continuing basis) of use of alcohol, sedatives, hypnotics, stimulants, narcotics, hallucinogens, marijuana, or inhalants.

The inhalant group was matched on sex, age, and ethnicity with 162 noninhalant polydrug users and 162 nondrug users. In addition, the polydrug users were selected from the PIR data base to match the inhalants' drug history. The criteria for matching drug 
Table 12

Inhalant Effects

\begin{tabular}{|c|c|c|c|c|c|}
\hline & I & $P$ & $\mathrm{p}_{1}$ & ND & $\mathrm{p}_{2}$ \\
\hline & \multicolumn{5}{|c|}{ Appearance } \\
\hline Poor Hygiene & .753 & .494 & .01 & .401 & .001 \\
\hline \multirow[t]{2}{*}{ Inappropriate Dress } & .370 & .173 & .01 & .124 & .001 \\
\hline & \multicolumn{5}{|c|}{ Cognitive Difficulties } \\
\hline Loss of Immediate Recall & .278 & .136 & .05 & .117 & .05 \\
\hline Abstraction Deficit & .772 & .512 & .05 & .401 & .005 \\
\hline Insight Deficit & 1.642 & 1.179 & .005 & .889 & .001 \\
\hline \multirow[t]{2}{*}{ Judgment Deficits } & 1.914 & 1.432 & .001 & 1.043 & .001 \\
\hline & \multicolumn{5}{|c|}{ Intra-/Interpersonal Difficulties } \\
\hline Withdrawal/Isolation & .827 & .525 & .01 & .562 & .05 \\
\hline Suspiciousness/Hostility & .741 & .722 & .05 & .494 & .05 \\
\hline Dissociation/Depersonalization & .154 & .056 & .05 & .049 & .05 \\
\hline Sexual Difficulties & .568 & .377 & .05 & .117 & .001 \\
\hline Marital Discord & .537 & .414 & .05 & .278 & .05 \\
\hline Family Discord & 1.333 & 1.204 & .05 & .593 & .001 \\
\hline School Problems & .661 & .438 & .05 & .259 & .005 \\
\hline Employment Problems & 1.136 & .963 & .05 & .407 & .001 \\
\hline \multirow[t]{2}{*}{ Trouble with the Law } & .673 & .500 & .05 & .216 & .001 \\
\hline & \multicolumn{5}{|c|}{ Physical and Somatic Difficulties } \\
\hline \multirow[t]{2}{*}{ Increased Sleep } & .148 & .043 & .05 & .006 & .005 \\
\hline & \multicolumn{5}{|c|}{ Danger to Self and Others } \\
\hline Potential Danger to Self & 1.389 & .969 & .001 & .704 & .001 \\
\hline Potential Danger to Others & 1.019 & .586 & .001 & .420 & .001 \\
\hline
\end{tabular}

Note- $p_{1}=$ probability level associated with ANOVA between the I and P groups, and $p_{2}=$ probability level associated with ANOVA among the three groups ( $p s<$ value given).

histories were number and kinds of drugs, severity of use, and duration of use.

The linked computer systems described previously accessed a library of programs and statistical packages for computing the descriptive statistics, analyses of variance (ANOVA), and the chi-square analyses that are reported below.

Three independent variables were used: group, ethnicity, and sex. Levels of each are as follows: inhalants vs. polydrugs vs. no drugs, black vs. Mexican vs. Anglo, by sex. A between-patients research design with an ANOVA of severity scores was utilized for those PIR variables for which estimates of severity were made.

Frequency counts of presence-absence data on each of 17 PIR variables for the 486 patients provided a 3 by 3 by 2 frequency table chi-square analyses. Similarly, chi-square analyses of frequency counts of presence-absence data provided comparative statistics among the independent variables for psychiatric history, psychiatric diagnosis, disposition, history and mental status, drug and alcohol abuse, and danger to self and others.

Altogether, some 87 PIR variables were examined statistically. Only those variables that discriminated among the three experimental groups yielding significant main interaction effects are reported below.

The inhalant group received the highest mean severity scores on the majority of clinical variables yielding
Table 13

Danger-to-Self-and-Other Variables Differentiating $I$ and $P$ Groups

\begin{tabular}{lcccc}
\hline & & \multicolumn{3}{c}{ Past (in Months) } \\
\cline { 4 - 5 } & Recent & 6 & $6-24$ & $24+$ \\
\hline $\begin{array}{l}\text { Thoughts of Suicide } \\
\text { Suicidal Behavior }\end{array}$ & & & .05 & .001 \\
Other Self-Destructive Behavior & .02 & .05 & & .001 \\
\hline
\end{tabular}

Note $-p<$ value given.

Table 14

Comparative Diagnoses of Patients in Three Study Groups

\begin{tabular}{lrrr}
\hline & I & PD & ND \\
\hline Psychotic Organic Brain Syndrome & 7 & 6 & 1 \\
Nonpsychotic Organic Brain Syndrome & 4 & 2 & 2 \\
Affective Psychosis & 4 & 4 & 4 \\
Nonaffective Psychosis & 23 & 19 & 26 \\
Neurosis & 15 & 15 & 15 \\
Personality Disorder & 20 & 0 & 0 \\
Sexual Deviation & 2 & 1 & 1 \\
Alcoholism & 8 & 7 & 1 \\
Drug Dependence & 35 & 17 & 1 \\
Psychophysiological Disorder & 0 & 0 & 2 \\
Transient Situational Disturbance & 10 & 15 & 19 \\
Behavior Disorder of Childhood or Adolescence & 15 & 10 & 7 \\
Mental Retardation & 1 & 6 & 8 \\
No Diagnosis Made & 2 & 5 & 15 \\
\hline
\end{tabular}

Note-Values are given in percentages. Based on $N=162$ psychiatric emergency room patients per group; percentages include primary and secondary diagnoses. 
Table 15

Post-Emergency Room Disposition for Three Study Groups

\begin{tabular}{lccc}
\hline & $\begin{array}{c}\text { Home or } \\
\text { Outpatient }\end{array}$ & Hospital & Left \\
\hline Inhalants & 27 & 64 & 9 \\
Polydrugs & 43 & 49 & 8 \\
Nondrugs & 39 & 45 & 16 \\
\hline
\end{tabular}

Note- $\chi^{2}=16.43(p<.002)$. Values are given in percentages.

Table 16

Duration of Illnesses for Study Groups

\begin{tabular}{lcccc} 
& & \multicolumn{3}{c}{ Duration (in Months) } \\
\cline { 3 - 5 } & $\mathrm{N}$ & $0-6$ & $6-24$ & $24+$ \\
\hline Inhalants & 124 & 15 & 19 & 66 \\
Polydrugs & 137 & 30 & 17 & 53 \\
Nondrugs & 111 & 37 & 16 & 47 \\
\hline
\end{tabular}

Note $-\chi^{2}=16.22(p<.01)$. Values listed for durations are given in percentages.

statistically significant findings. These 24 clinical variables and, when applicable, corresponding group mean severity scores and probability values indicating significant differences between groups are presented in Tables 12-16.

The inhalant group evidences more self- and otherdirected aggressive behavior, a wider range of cognitive deficits, and more extensive social disruption than the other two groups. Inhalant users, however, were not significantly different in emotional dyscontrol or intelligence. Significantly more diagnoses of personality disorders and drug dependency were recorded for inhalant users; their difficulties tended to be more longstanding, and their disposition included hospitalization more frequently.

\section{COMMENT}

The above series of studies demonstrated the utility of an information processing system in a PER. The diversity of projects pursued attested to the flexibility inherent in such a system. Studies above ranged from an overall description of the PER casualty through various groupings of the patients to small special-interest patient groups. Again, the versatility of the system permitted us to employ a range of research methodologies to focus on patient populations and research problems of interest. The utility of this interface between computer science, medicine, and the behavioral sciences is evidenced by this collaborative effort.

\section{REFERENCE NOTES}

1. Peterson, L. L., Mays, S. G., Wiederman, S., Mishelevich, D. J., Trimboli, F., \& Cody, V. F. A direct information processing system for a psychiatric emergency room. Fifth Annual Scientific Forum of the Society for Computer Medicine, Chicago, 1975.
2. Peterson, L., Mays, S., Dana, K., Wiedeman, S., Semler, I., Trimboli, F., \& Korman, M. An information storage and retrieval system for the psychiatric emergency room: Use of the data. Paper presented at the UTRCC Computing Conference, University of Texas Regional Computer Center, Dallas, Tex., 1977.

3. Barr, A. J., Goodnight, J. H., Sall, J. P., \& Helwig, J. T. The user's guide to SAS.76. Raleigh, N.C: SAS Institute, North Carolina, 1976.

4. American Psychiatric Association. Diagnostic and statistical manual of mental disorders (3rd ed.). Washington, D.C: Author, 1978. (Draft)

5. Sharp, C. W., \& Brehm, M. L. (Eds.). Review of inhalants: Euphoria to dysfunction. National Institute of Drug Abuse Research Monograph, 1977.

6. Vargas, P. A preliminary assessment of NIDA programs and activities regarding the inhalation of toxic substances as a drug abuse problem. Special Report to the Director of the National Institute on Drug Abuse, 1975.

7. Korman, M. Clinical evaluation of psychological factors. In C. W. Sharp \& M. L. Brehm (Eds.), Review of inhalants: Euphoria to dysfunction. National Institute of Drug Abuse Research Monograph, 1977.

\section{REFERENCES}

ATKıns, R. W. Psychiatric emergency service: Implications for the patient, the physician, the family, the hospital and the community. Archives of General Psychiatry, 1967, 17, 176-182.

Baxter, S., Chodorkoff, B., \& Underhill, R. Psychiatric emergencies: Dispositional determinants and the validity of the decision to admit. American Journal of Psychiatry, 1968, 124, 1542-1548.

Buss, C. I. Statistics in biology (Vol. 1). New York: MoGraw-Hill, 1967.

Chafetz, M. E. The effect of a psychiatric emergency service on motivation for psychiatric treatment. Journal of Nervous and Mental Disorders, 1965, 140, 442-448.

Contrenas Perez, C. M. Inhalacion voluntaria de disolventes industriales. Mexico City: Editorial Trillas, 1977.

Climent, C. E., Plutchix, R., Estrade, H., Gaviria, L. F., \& Arevalo, W. A comparison of traditional and symptomchecklist based histories. American Journal of Psychiatry, 1974, 132, 450-453.

Dregsler, D. M., Prusoff, B., Mark, H., \& Shapiro, D. Clinician attitudes toward the suicide attempter. Journal of Nervous and Mental Disorders, 1975, 160, 146-155.

EndicotT, J., \& Spitzer, R. L. The value of the standardized interview for the evaluation of psychopathology. Journal of Personality Assessment, 1972, 36, 410-417.

Freeman, H. L., \& Roy, R. G. Some comparative studies of psychiatric emergencies. Comprehensive Psychiatry, 1971, 12, 208-216.

HrBBERD, T. E. Patient characteristics related to outcome of psychiatric hospitalization. Unpublished doctoral dissertation, University of Texas Health Science Center at Dallas, Dallas, Texas, 1980.

Huffine, C. L., \& Craig, T. J. Social factors in the utilization of an urban psychiatric emergency service. Archives of General Psychiatry, 1974, 30, 249-255.

Lazare, A. The psychiatric examination in the walk-in clinic: Hypothesis generation and hypothesis testing. Archives of General Psychiatry, 1976, 33, 96-102.

LuBonsкY, L., \& BАснRАCH, H. Factors influencing clinicians' judgments of mental health. Eighteen experiences with the health-sickness rating scale. Archives of General Psychiatry, 1974, 31, 292-299.

Maxmen, J. S., Tucker, G. J., \& LeBow, M. Rational hospital psychiatry: The reactive environment. New York: Brunnermazel, 1974. 
Miller, W. B. A psychiatric emergency service and some treatment concepts. American Journal of Psychiatry, 1968, 124, 84-92.

Muller, J. J., Chafetz, M. E., \& Blane, H. T. Acute psychiatric services in the general hospital: III. Statistical survey. American Journal of Psychiatry, 1967, 124, 46-57.

Munves, P. I. The repeat visit phenomenon in the psychiatric emergency room. Unpublished doctoral dissertation, University of Texas Health Science Center at Dallas, 1977.

Newmark, C., Falk, R., Boren, R., \& Finch, A., Jh. Validation of an empirically derived set of symptom clusters to diagnose schizophrenia. Journal of Clinical Psychology, 1976, 32, 459-463.

Nie, N. H., Hull, C. H., Jenkins, J. G., Steinbrenner, K., \& BENT, D. H. SPSS: Statistical package for the social sciences (2nd ed.), New York: McGraw-Hill, 1975.

Potkay, C. R. The role of personal history data in clinical judgment: A selective focus. Journal of Personality Assessment, 1973, 37, 203-212.

Rabinen, C. J., \& Lunie, A. The case for psychiatric hospitalization. American Journal of Psychiatry, 1974, 131, 761-764.

Raphling, D. L., \& Lion, J. Patients with repeated admissions to a psychiatric emergency service. Community Mental Health Journal, 1970, 6, 313-318.

Roberts, B. A look at psychiatric decision making. American Journal of Psychiatry, 1978, 135, 1384-1387.

Schwartz, D. A., Weiss, A. T., \& Miner, J. M. Community psychiatry and emergency service. American Journal of Psychiatry, 1972, 129, 710-714.

Segal, J. (Eds.). Research in the service of mental health: Report of the Research Task Force of the National Institute of Mental Health. Rockville, Md: National Institute of Mental Health, 1975.

Spitzer, R. L., \& Fleiss, J. L. A reanalysis of the reliability of psychiatric diagnosis. British Journal of Psychiatry, 1974, 125, 341-347.

Straker, M., Yung, C., \& Weiss, L. A comprehensive emergency psychiatric service in a general hospital. Canadian Psychiatric Association Journal, 1971, 16, 137-139.

Tischler, G. L. Decision-making process in the emergency room. archives of General Psychiatry, 1966, 14, 69-78.

UNGerle IDER, J. T. The psychiatric emergency. Analysis of six months experience of a university hospital's consultation service. Archives of General Psychiatry, 1960, 3, 593-601.

VAN Hoose, T. A. The contribution of demographic, clinical interview, and clinical judgment variables in the diagnosis of psychiatric emergency patients. Unpublished doctoral dissertation, University of Texas Health Science Center at Dallas, 1976.

Wing, J. K. The social context of schizophrenia. American Journal of Psychiatry, 1978, 135, 1333-1339.

Yusin, A., Nihara, K., \& Mortashed, C. Major and minor criteria in schizophrenia. American Journal of Psychiatry, 1974, 131, 688-692. 